\title{
MADAME DE STAËL Y LA CONSITUCIÓN DEL AÑO III: EL NACIMIENTO DEL REPUBLICANISMO LIBERAL
}

\section{MADAME DE STAËL AND THE CONSTITUTION OF THE YEAR III: THE BIRTH OF THE LIBERAL REPUBLICANISM}

\author{
María Luisa Sánchez-Mejía \\ Universidad Complutense de Madrid
}

SUMARIO: I. LA CONSTITUCIÓN DEL AÑO III.- II. LA FORMACIÓN DE MADAME DE STAËL.- III. LOS INICIOS DEL REPUBLICANISMO LIBERAL.- IV.- LA FIRMEZA DEL EJECUTIVO.- V. MORAL, RELIGIÓN Y SOCIEDAD

\begin{abstract}
Resumen: En turbulento periodo que va de Termidor a Brumario, en los años postreros de la Revolución francesa, Madame de Staël desempeñó un papel fundamental en la construcción del republicanismo liberal. Su obra Des circonstances actuelles qui peuvent terminer la Révolution et des principes qui doivent fonder la république en France contiene una propuesta de república moderada y plural, y una modificación de la Constitution de l'an III, para corregir los defectos que han obligado al régimen del Directorio a sostener la república a través del golpe de estado y la violencia política.
\end{abstract}

\begin{abstract}
In the aftermath of the French Revolution, during the stormy days between Termidor and Brumaire, Mme. de Staël played a fundamental role in the formation of liberal republicanism. Her book, Des circonstances actuelles qui peuvent terminer la Révolution et des principes qui doivent fonder la république en France, presented a template for a moderate and pluralistic republic, as much as it showed how to reform the Constitution de l'An III in order to fix those mistakes which forced the Directoire to sustain the republic by means of coup d'états and political violence.
\end{abstract}

Palabras Clave: Madame de Staël, republicanismo liberal, Francia, Constitución año III

Key Words: Madame de Staël, liberal repulicanism, France, Constitution of Year III

En el campo de la teoría política no ha habido mucho espacio para las mujeres. Ni siquiera en el de la política práctica, si exceptuamos a reinas o regentes. Y en esa conjunción de teoría y aplicación práctica que es el derecho constitucional, apenas encontramos nombres femeninos. En los inicios del constitucionalismo moderno, el más destacado, por no decir el único, es el de Germaine de Staël, protagonista indiscutible del agitado periodo que va de Termidor a Brumario, en los años postreros de la Revolución francesa.

Poner fin a la Revolución y conservar a la vez los principios nacidos de 1789 era una tarea dificil, para la que no había hoja de ruta, y que se veía continuamente obstaculizada por los restos del radicalismo montagnard, desde la izquierda, y por los afanes de revancha de los exilados contrarrevolucionarios, 
que habian iniciado el regreso a Francia tras la caída de Robespierre ${ }^{1}$. La tarea más urgente era crear unas instituciones que aseguraran cierta estabilidad política, y asentaran la república sobre bases amplias, para reemplazar el estado revolucionario por un orden constitucional, lo que el periodista Adrien Lezay llamaba "un nuevo contrato social"2 . De esa necesidad nació la llamada Constitución del Año III, envuelta en amplias polémicas, antes y después de su promulgación, Estas polémicas muestran la complejidad de la transición desde una democracia de inspiración roussoniana a un republicanismo de corte liberal, que, con independencia de la forma de gobierno que se adopte, va a marcar todo el siglo XIX.

En esta etapa crucial para el devenir del pensamiento político europeo, Germaine de Staël se mantiene en un primer plano, tanto en actividad política como en producción teórica, aunque su obra principal no llegue a ver la luz editorial. El hecho de ser mujer condicionó sin embargo el juicio no solo de sus contemporáneos sino el de buena parte de los historiadores que, incluso a finales del siglo XX, siguen viendo en ella más su "lado femenino" que sus aportaciones intelectuales: anfitriona perfecta, salonnière brillante, sombra influyente de politicos a la moda... , y, además, con los vicios que los tópicos atribuyen a las mujeres que actúan en la esfera pública: ambiciosa, intrigante y desleal ${ }^{3}$. Es cierto que, al no poder subir a las tribunas de las Asambleas o de los clubes, las mujeres habian encontrado, desde 1791, la forma de participar en la revolución a través de los salones: dictaban, corregían, o rehacian los discursos que se pronunciarian al día siguiente; iban a oírlos, juzgaban y sostenían con su presencia al orador débil o tímido, y le defendian ante los poderosos para que obtuvieran su favor ${ }^{4}$. Y es cierto también, que vedados los cargos políticos a las mujeres, Madame de Staël tuvo que actuar a veces a través de hombres a los que aupaba a los puestos que no podía ocupar directamente. Sin embargo habia hecho algo más que alentar las ambiciones de aspirantes a cargos públicos. En 1794 y 1795 había escrito dos opúsculos analizando la situación política del momento, como veremos, y en 1796 había publicado una obra sobre el comportamiento humano en clave politica. Y ese mismo año iniciaba la redacción de un gran libro sobre la Constitución del año III, que terminó en 1798, y que fue bien conocido y comentado en los círculos políticos de la época -aunque quedó sin publicar- y del que nos ocuparemos en estas páginas. Es hora pues de abandonar los lugares comunes sobre madamas y salones, y atender a una de las aportaciones más notables del laboratorio político termidoriano.

\footnotetext{
1 Para las agitaciones politicas de Termidor y del Directorio vid. Jean-Clément Martin, Nueva historia de la Revolución francesa, Barcelona, Crítica, 2013, traducción de Palmira Feixas, capítulos 19 y 20, pp. 443-501, y los estudios ya clásicos de Bronislaw Baczko, Comment sortir de la Terreur. Thérmidor et la Révolution, Paris, Gallimard, 1989; Denis Woronoff, La République bourgeoise : de Thermidor à Brumaire, 1794-1799, Paris, Seuil, 1972; François Furet, La Révolution. De Turgot á Jules Ferry, Paris, Hachette, 1988, cap. 4: "La République Thérmidorienne, 1794-1799".

2 Andrew Jainchill. Reimagining Politics after the Terror. The Republican Origins of French Liberalism. Ithaca and London, Cornell University Press, 2008, p. 26. Adrien de Lezay habia publicado Qu'est-ce que la constitution de 95, Paris 1795 (año III).
}

3 Bronislaw Baczko, Politiques de la Révolution française, Paris Gallimard, 2008, cap. 6: "Utopie salonnière et réalisme politique".

4 Ibid. p. 363. 


\section{LA CONSTITUCIÓN DEL AÑO III}

A la caída de Robespierre, - en julio de 1794, Termidor año II- estaba vigente la Constitución de 1793, aunque continuaba durmiendo en el arca de madera de cedro donde había sido confinada el mismo día de su aprobación en referendum, en espera del fin de la guerra ${ }^{5}$. De carácter muy democrático, la Constitución jacobina había previsto un legislativo fuerte, y siempre vigilante, y un ejecutivo mucho más débil, de carácter múltiple, formado por veinticuatro ministros. Este gobierno era igualmente elegido por la Asamblea, a partir de una lista preparada por las asambleas electorales de los Departamentos, a razón de un candidato por Departamento. La dificultad, imposibilidad en la práctica, de que un ejecutivo así compuesto pudiera concertar sus voluntades para tomar decisiones de manera ágil y eficaz, colocaba a este ministerio en dependencia constante de la Asamblea. La prohibición constitucional de nombrar un jefe supremo del ejército y la ausencia de altas instituciones en la administración de justicia (Tribunal Supremo o Tribunal Constitucional), para evitar rivales a la Asamblea, convertía a ésta en poder supremo, pero un poder ralentizado por la obligación de someter a referendum todas las leyes para su aprobación definitiva ${ }^{6}$. Este maquinaria democrática, con fuertes ecos roussonianos, era muy poco conveniente para una nación en guerra, una situación que exigía poderes firmes y decisiones rápidas. En su lugar se erigió el tristemente célebre Comité de Salut Publique, que actuó como el ejecutivo fuerte y tiránico que la Constitución había querido conjurar, pero que reinaba de manera interina, a la espera de que tiempos mejores permitieran despertar a la Constitución de su placido sueño en arca de cedro. Abatida la férrea mano de Robespierre, la Convención Termidoriana debía ser el príncipe que despertara por fin a la bella durmiente, aunque las cosas acabarian sucediendo de otra manera.

Pero el Terror había cambiado tanto a la Revolución que iba a resultar imposible reconocerse en la Constitución de 1793, redactada en plena euforia republicana, cuando la abolición de la monarquía había dado paso a un tiempo nuevo que veía la utopía al alcance de la mano. En aquel momento La Asamblea había invitado a "todos los amigos de la libertad y de la igualdad" del mundo entero a enviar sus ideas y había propuesto que los mejores especialistas de Francia examinaran con detenimiento cada proyecto, para que los mejores legisladores dieran a la luz la mejor de las repúblicas ${ }^{7}$. Los termidorianos en cambio tenían un objetivo mucho más modesto: restablecer la convivencia, buscar un amplio consenso, defender la propiedad y, sobre todo, fundar unas instituciones para existir en un tiempo humano y secular, caracterizado por la contingencia y la inestabilidad ${ }^{8}$.

Sin embargo, igual que Condorcet y los hombres del 93, los termidorianos seguían desconfiando del poder gubernamental, primero porque había estado en

\footnotetext{
5 El 10 de agosto de 1793, al finalizar la fiesta revolucionaria celebrada para conmemorar el primer aniversario de la jornada del 10 de agosto de 1792 y la aprobación en referéndum de la Constitución, el texto fue encerrado en el cofre de cedro y depositado en la sala de la Convención, a los pies de la presidencia, para esperar la llegada de la paz: Les Constitutions de la France depuis 1789, Paris, Flammarion, 1995, p. 76.

6 Ibid. pp. 69 y ss.

7 Ibid. p. 70.

8 Andrew Jainchill. Reimagining Politics after the Terror, op. cit., p. 33.
} 
manos de un monarca absoluto, y segundo porque había estado en manos del Comité de Salut Publique que, aun con su carácter provisional, se había mostrado como un ejecutivo fuerte, demasiado fuerte. Además los convencionales de Termidor eran todavía los hijos de la Revolución y muchos regicidas se sentaban aun en la Asamblea. Deseaban terminar la Revolución apropiándosela, como habían hecho con Rousseau, al decretar el traslado solemne de sus restos al Panteón.

En este dificil equilibrio, la Constitución del año III, obra fundamentalmente de Pierre Daunou, del círculo de los Ideólogos, reconocía la supremacía de la ley como expresión de la voluntad general, y recogía una nueva Declaración de Derechos que aseguraba la igualdad civil y la libertad. La Constitución ponía el acento en la defensa de la propiedad, a través de un sistema electoral censitario e indirecto: todos los ciudadanos que pagaran impuestos eran electores de primer grado, pero solo eran elegibles para un segundo nivel los propietarios que pudieran demostrar unas determinadas rentas, que variaban según las circunscripciones.

La desconfianza hacia el poder ejecutivo llevó a Daunou y a la Comisión de los Once a reforzar el legislativo -como habia hecho el texto de 1793- pero con muchas más cautelas: se establecieron dos Cámaras, el Conseil de Cinq Cents, y el Conseil des Anciens, el primero proponía las leyes y el segundo las aprobaba o rechazaba. Al primero se podía acceder a partir de los treinta años, al segundo solo después de haber cumplido los cuarenta: los Ancianos era una cámara alta, integrada por doscientos cincuenta miembros, a quienes la edad debia proporcionar la experiencia y la prudencia necesarias para refrenar los entusiasmos revolucionarios -o contrarrevolucionarios- de los Quinientos, pero su tarea principal era la designación del Ejecutivo, a partir de una lista presentada por aquellos. A medio camino entre los delegados, según el proyecto roussoniano -recogido en la figura de los veinticuatro ministros de la Constitución de 1793- y el modelo posterior de un Presidente del Gobierno, los constitucionales del año III optaron por lo que Constant llamará un ejecutivo complejo ("la complexité) $)^{9}$ : un órgano colegiado formado por cinco Directores y por los ministros, aunque estos últimos asumian tareas más de administración que de decisión política. Las dos cámaras se debían renovar por tercios cada año, y un sorteo decidia cuál de los cinco directores debía ceder anualmente su puesto a un nuevo miembro recién nombrado.

El problema principal que presentaba este entramado institucional era la ausencia de un poder supremo, situado por encima de los dos poderes tradicionales. La comisión encargada de la redacción del texto no quiso aceptar la sugerencia de Sieyès de crear un Tribunal Constitucional, un órgano que velara por la adecuación de las leyes a la Constitución y que se situara por encima de las tendencias políticas reflejadas en las Cámaras ${ }^{10}$. No había tampoco ningún

\footnotetext{
9 Benjamin Constant distingue entre l'unité, el ejecutivo con un jefe único a la cabeza, y la complexité, el ejecutivo formado por varios gobernantes, y propio de las repúblicas. Aunque escribe ya en 1803, el modelo del Directorio sigue vigente en el pensamiento republicano: Benjamin Constant, De la possibilité d'une constitution républicaine dans un grand pays (17991803), en Oeuvres Complètes, vol. IV, edición de María Luisa Sánchez-Mejía, Tübingen , Max Niemeyer Verlag, 2005. Hay traducción española: Una constitución para la república de los modernos, Madrid, Tecnos, 2013, traducción de Ana Portuondo.

10 Vid. "Opinión de Sieyès sobre las atribuciones y organización del Tribunal Constitucional. Discurso pronunciado en la Convención nacional el 18 de Termidor, año III de la República”, en
} 
control sobre el ejecutivo, salvo su fraccionamiento o complexité, fuente de disensiones internas. La única forma de impedir una actuación excesivamente independiente por parte del Directorio era acusar y enjuiciar oficialmente a alguno de sus miembros, solución tan excesiva que resultaba inútil en la práctica. En realidad, el contrapeso no existía, y la división de poderes no era efectiva, ya que tanto las Cámaras como el Directorio quedaban sin control. El resultado fue el contrario a la intención de los legisladores: la inestabilidad presidió el periodo en que estuvo vigente la Constitución del año III, y solo se pudo paliar con medidas anticonstitucionales.

Las irregularidades comenzaron inmediatamente: una vez aprobada la Constitución se decidió que dos tercios de los nuevos diputados debían elegirse entre los que ya se sentaban en los bancos de la Convención. Las elecciones del nuevo régimen quedaban así falseadas, ya que se garantizaba una mayoría republicana sin pasar por las urnas, sino coaccionando el voto de los electores de segundo nivel, encargados de nombrar a los representantes. Este decreto de los dos tercios y la obligada presencia de quienes serian llamados "los perpetuos" enajenó al Directorio la adhesión de una derecha monárquica que esperaba amplia representación tras las elecciones. Bloquearon a cambio un giro contrarrevolucionario que hubiera comprometido gravemente la obra de la Revolución y la seguridad de los regicidas que todavía formaban parte de la asamblea termidoriana.

Pero era una garantía efimera. Precisamente para evitar que los diputados se perpetuaran en el poder, la Constitución preveía que cada año se renovara un tercio de los miembros de las Cámaras. De manera que en 1797, la debilidad de la república volvió a ponerse de manifiesto. Al no poder seguir decretando la permanencia de los antiguos convencionales, las elecciones fueron libres y dieron mayoría a diputados monárquicos, que ocuparon la presidencia de ambas Cámaras, la jefatura suprema del ejército y el puesto vacante en el Directorio, después de su también obligada renovación anual. En pocos dias toda la obra tan cuidadosamente construída por la Convención Termidoriana amenazaba con derrumbarse y arrastrar a la república en su caída. No quedaba otro recurso que un golpe de fuerza. El general Hoche, llamado por el Directorio, ocupó París y obligó a las Cámaras a anular las elecciones y a eliminar del legislativo a todos los diputados pro monárquicos. Cincuenta y dos diputados, dos Directores y los realistas más destacados fueron detenidos y deportados a la Guayana. Es el golpe de estado de 18 Fructidor (4 de septiembre de 1797), que dejó a la Constitución y al régimen que había alumbrado heridos de muerte. La represión que sucedió al golpe, con ciento sesenta condenas a muerte, cientos de arrestados y deportados sin juicio y retirada de derechos cívicos a los nobles y a los parientes de los emigrados, instaló la arbitrariedad donde debía haber estado la ley. La república tenia ya sus dias contados.

Sieyès, Escritos y discursos de la Revolución, Madrid, Centro de Estudios Politicos y Constitucionales, 1990, pp. 273 y ss. La necesidad de un cuarto poder, que garantizara la estabilidad por encima de los enfrentamientos entre legislativo, ejecutivo y judicial venía de los inicios de la Revolución: vid. Marcel Gauchet, La révolution des pouvoirs, Paris, Gallimard, 1995. 


\section{LA FORMACIÓN DE MADAME DE STAËL}

En medio de la tormenta política que sacude al Directorio, Germaine de Staël, políticamente muy activa desde su llegada a París en mayo de 1795, decide elaborar una reflexión en profundidad sobre los acontecimientos que está viviendo, encuadrándolos en todo el proceso revolucionario $\mathrm{y}$, en última instancia, en una interpretación general del paso de una monarquía absoluta a una república más acorde con las exigencias de los tiempos. El hilo conductor de esta reflexión será la Constitución del Año III y sus consecuencias para el régimen del Directorio, y el título provisional de su obra: Des circonstances actuelles qui peuvent terminer la révolution et des principes qui doivent fonder la république en France ${ }^{11}$.

No era la primera obra política que escribía, como ya se ha dicho. En 1794, poco después de la caída de Robespierre, había publicado unas Refléxions sur la paix adressèes a M. Pitt et aux Français, en la que aparecía ya la necesidad de poner fin a la Revolución, y pedía a Inglaterra el reconocimiento de la república y la renuncia a la guerra. En su opinión, la guerra exterior había sido la causa principal del radicalismo revolucionario: la presencia en suelo francés de tropas de ocupación extranjeras, en nombre de los derechos de un rey absoluto, había producido un movimiento de adhesión a los ideales revolucionarios, a pesar de los crimenes y el despotismo del gobierno que los representaba.

A finales de 1795 redactó unas segundas reflexiones, tituladas esta vez Réflexions sur la paix intérieur, que eran ya una defensa abierta de la república con los mismos argumentos que va a recoger en Les circonstances actuelles...., pero que los acontecimientos políticos de Vendimiario, a raíz del polémico decreto de los dos tercios, aconsejan no publicar porque en ella proponía a los monárquicos moderados servirse precisamente de las elecciones para elegir hombres honestos que pudieran colaborar en la tarea de poner el punto final a la Revolución.

Ambas Reflexiones ${ }^{12}$ muestran una sólida formación en materia de teoría y de praxis política, que Madame de Staël no había adquirido solo como anfitriona de reuniones mundanas. En 1789 había contemplado el cortejo de los representantes de los Estados Generales desde una ventana del palacio de Versalles, donde su padre, Jacques Necker, aconsejaba al rey desde su cargo de Ministro de Finanzas. Es indudable que la influencia de su padre fue la más profunda y la más persistente en el pensamiento político de Germaine. Destituido en 1790, Necker se retiró a su chateau suizo, en Coppet, y se dedicó a escribir en defensa del oden y de la estabilidad política. La autoridad de Necker, fundada en su conocimiento y en su larga experiencia de la política francesa, fue asumida no solo por su hija Germaine sino por todo lo que se denomina hoy "el Grupo de

11 Des circonstances actuelles qui peuvent terminer la Révolution et des principes qui doivent fonder la république en France. Édition critique de Lucia Omacini, Paris-Genève, Droz, 1979. Las citas se harán de la edición española a cargo de María Luisa Sánchez-Mejía y traducción de Ana Portuondo, en Madame de Staël, Escritos politicos, y se citará en el texto y en las notas como Circunstancias.

12 Refléxions sur la paix adressèes a M. Pitt et aux Français se publicó en Suiza en 1794 y en una segunda edición en París en 1795. Las Refléxions sur la paix intérieur se escribió en el verano de 1795, pero nunca se publicó. Hay edición española en Madame de Staël, Escritos politicos, op. cit. 
Madame de Staël y la Constitución del año III: el nacimiento del republicanismo liberal

Coppet", esos "Estados Generales de la opinión europea", como los llamará Stendhal, generador de cultura y de reflexiones políticas ${ }^{13}$.

En el caso de Benjamin Constant no se puede hablar de influencia sino de colaboración entre ambos autores desde que llegan juntos a París en 1795: la defensa de la obra de la Revolución y la condena del Terror, la necesidad de sostener la república desde la moderación, que aleje tanto a la contrarrevolución como al radicalismo izquierdista, son argumentos que se pueden encontrar tanto en las Reflexiones de Madame de Staël como en De la force du gouvernement actuel $^{14}$, que Constant publica en 1796. Ideas importantes incluidas en las Circunstancias de Mme de Staël, como la famosa distinción entre la libertad de los antiguos y la de los modernos, serán después publicitadas por Constant en sus propias obras. Constant fue para Germaine de Staël una compañia intelectual con quien compartió ideas, discusiones y proyectos políticos. Cada uno fue una buena escuela para el otro y el ambiente de la época su campo de estudio y de experiencia ${ }^{15}$.

Una experiencia politica que tuvo que ser indirecta, por "persona interpuesta", como decíamos antes. En 1791 fue "Ministra de la Guerra" a través del nombramiento que para ese ministerio obtuvo su amante del momento Louis Narbonne. Cuando la reina María Antonieta se enteró del nombramiento comentó: "Quelle gloire pour Mme. de Staël et quel plaisir pour elle d'avoir ainsi toute l'armée ... à elle!"16. Gran señor, hijo natural quizá de Luís XV y partidario de un régimen constitucional, Narbonne podía aspirar a lo más alto y Germaine logró situarlo en primera fila. Los discursos de Narbonne en esa etapa son todavía objeto de estudio para rastrear en ellos las ideas staëlianas de moderación y de llamamiento a la opinión pública, que defendian ambos en aquel momento $^{17}$, y aunque ella no escribiera los discursos de su amante, hay que suponer de nuevo la "comunión de ideas", la discusión fructifera y la vivencias políticas compartidas.

Con el conde Ribbing fracasará en su intento de incorporarle como oficial del ejército francés, pero descubrirá con él las razones para tomar partido en favor de una república. Adolphe Ribbing, ex-oficial del ejército sueco, había participado en la conjura para asesinar al rey Gustavo III, y habia sido condenado por el magnicidio y luego indultado. Exilado en Francia, Madame de Staël, esposa del embajador de Suecia en París, encontró en él no solo amor y amistad sino una

13Étienne Hofmann et François Rosset, Le groupe de Coppet, une constellation d'intellectuels européens, Presses polytechniques et universitaires romandes, 2005.

14 Benjamin Constant, De la force du Gouvernement actuel et de la nécessité de s'y rallier, s.1. , año IV.

15 Constant seleccionó e hizo copiar para su propio uso determinados pasajes de las Circunstancias, que utilizó posteriormente en sus obras. Vid. Lucia Omacini, "Introduction" a Des circonstances actuelles..., op. cit. pp. LXVII-LXX; LXXXII-LXXXIV, y "Benjamin Constant correcteur de Madame de Staël”, Cahiers staëliens, $\mathrm{n}^{\circ}$ 25, 1978, así como Roswitha Schatzer, "Introduction" à Benjamin Constant, "Copie partielle" de Des circonstances actuelles de Madame de Staël, en Benjamin Constant Oeuvres Complètes, op. cit., vol. IV.

16 John Isbell, "Madame de Staël, Ministre de la Guerre?. Les discours de Narbonne devant 1'Assemblée législative", Annales historiques de la Révolution française, n 307, 1997, pp. 93-104.

17 Madame de Staël había publicado en la prensa un artículo titulado "A quels signes peut-on connaître quelle est l'opinion de la majorité de la nation?". Ibid. p. 98. 
influencia decisiva para acelerar su evolución personal y adquirir sólidas convicciones republicanas ${ }^{18}$

Constant le debe en cambio su introducción en los círculos intelectuales y políticos del París de Termidor, y el primer cargo que ocupó: concejal en la comuna de Luzarches, en 1797, a pesar de su origen suizo y de que se habia rechazado por dos veces su petición de la nacionalidad francesa, y, después del 18 brumario, su nombramiento como miembro del Tribunado, uno de los órganos legislativos del Consulado ${ }^{19}$.

Sin embargo, su experiencia política más cercana y más dolorosa fue precisamente el golpe de 18 fructidor, la violación de la Constitución del Año III por parte del Directorio para salvar la república que esa misma constitución había instaurado. La participación de la pareja Staël-Constant en la conspiración que dio lugar al golpe de estado desde el propio régimen parece fuera de duda, aunque la represión que siguió no permitió reivindicarlo. "Fructidorienne malhereuse" o "fructidorienne honteuse", la llama Furet ${ }^{20}$, porque Germaine siempre condenó el golpe, quizá con cierto sincero arrepentimiento, mientras Constant lo defendia con menos escrúpulos de conciencia y más realismo político $^{21}$. Lo que sí es cierto es que su participación activa o pasiva en las jornadas de fructidor llevaron a Mmed. de Staël a escribir sus Circunstancias....: una constitución que obligaba a un golpe de estado para mantenerla no era una buena constitución.

\section{LOS INICIOS DEL REPUBLICANISMO LIBERAL}

Las aproximaciones a la figura de Madame de Staël han intentado con frecuencia explicar el momento y las causas por las que primero se muestra republicana y más tarde liberal, por qué su apoyo entusiasta a la Revolución, y a la república que la encarna, se va enfriando hasta convertirse en una teórica del primer liberalismo, y han descrito esta trayectoria en base a elementos biográficos, a influencias externas o a la desilusión provocada por los acontecimientos políticos ${ }^{22}$. Todas estas interpretaciones imaginan al liberalismo confrontado con el republicanismo, como dos alternativas diferentes entre las que era preciso elegir, o como una -el liberalismo- posterior a la otra -el republicanismo-, y por tanto como un camino que se podia transitar en etapas.

El panorama político de Termidor primero y del Directorio después ofrecía unas opciones distintas de las que iban a dominar después el siglo XIX. La caída de Robespierre permitió volver a pensar en "hacer política" a personas y grupos que habían estado ocultos o exiliados durante el Terror. La primera gran

18 Simone Balayé, Madame de Staël. Lumières et liberté, Paris, Klincksieck, 1979, p. 47.

19 Constant fue nombrado por Napoleón, a instancias de Madame de Staël, miembro del Tribunado, uno de los dos órganos legislativos previstos por la Constitución del año VIII. Vid. Kurt Kloocke, Benjamin Constant. Une biographie intlectuelle, Genéve-Paris, Droz, 1984, p. 84.

20 Michel Winock, Madame de Staël, Paris, Fayard, 2010, p. 148.

21 Alain Laquièze, "Benjamin Constant et l'idée républicaine sous le Directoire", en Cahiers staëliens, $\mathrm{n}^{\circ} 58,2007$, pp. 121-136.

22 Andreas Kalyvas y Ira Katznelson, Liberal Beginnings. Making a Republic for the Moderns, Cambridge University Press, 2008, pp. 118-119. 
distinción estaba entre los defensores de la Revolución y los partidarios de la monarquía de Antiguo Régimen, que empezaron a regresar cuando dejaron de temer por sus vidas. Todavía bajo el shock de la ejecución de Luís XVI, los monárquicos no habian tenido tiempo ni ambiente propicio para evolucionar hacia lo que luego se llamará una monarquía constitucional ${ }^{23}$, y quedaban pues descartados por todos lo que no deseaban la contrarrevolución pura y dura. De manera que quienes no eran monárquicos absolutistas necesariamente habian de ser republicanos. ${ }^{24} \mathrm{Y}$ dentro de ellos la división era fundamentalmente entre radicales, o terroristas, y moderados a la busca de un centro o de un punto de convergencia que salvara a la Revolución poniéndole fin definitivamente. En este centro se construía lo que luego se llamará liberalismo, en un equilibrio casi imposible entre muchos extremos ${ }^{25}$.

Los ejes centrales de los debates: el modelo de sociedad, el sistema político y la organización de los poderes del estado, están presentes en todas las opciones y marcan la posición de unos y otros en el espectro político. Dentro del republicanismo hay además una preocupación siempre presente: las exigencias de los tiempos, las transformaciones que demanda la marcha de la Historia y, en definitiva, los rasgos que debe tener una república moderna. Y en todas estas discusiones, el centro, los moderados, combaten a derecha e izquierda, y van construyendo lo que hoy podemos llamar un republicanismo liberal.

El modelo de sociedad pasa, evidentemente, por la igualdad ante la ley y por la propiedad privada, rasgos primeros que diferencian el sistema nobiliario del posrevolucionario. La naturaleza, la extensión y el uso de la propiedad son los elementos que generan los matices entre las distintas opciones republicanas. La destrucción de los privilegios feudales llevó a los más radicales a la esperanza, y a los más conservadores al temor, de que los derechos de propiedad fueran los siguientes en caer bajo el golpe de la Revolución. Antoine Barnave, monárquico moderado, expresaba este temor ya en 1791, cuando los acontecimientos empezaban a precipitarse: "Todos ustedes saben que la noche del 4 de agosto dio a la Revolución más armas que todos los decretos constitucionales; pero para todos aquellos que querrian ir más allá, ¿qué noche del 4 de agosto queda por hacer sino la de decretar leyes contra la propiedad?"26. Sin embargo no hubo

23 Los monárquicos declaraban mantenerse fieles a lo que ellos mismos llamaban "l'antique et indéfectible constitution" y querian devolver al rey y a la nobleza todo su poder y sus prerrogativas. Vid.: Nicolas Jannon, Développement des principes fondamentaux de la monarchie française, (S. 1.,), 1795. Y Joseph de Maistre, en sus Considérations sur la France, publicada en 1796, al tiempo que Mme. de Staël terminaba la redacción de las Circunstancias, afirmaba que la victoria de la contrarrevolución era algo cierto e inevitable; vid. Jacques Godechot, La contrerévolution (1789-1804), Paris, P.U.F., 1984, p. 103.

${ }^{24}$ Una definición de lo que se entendía por república en ese momento se puede encontrar en Alain Laquièze, "Benjamin Constant et l'idée républicaine sous le Directoire", op. cit. p. 121.

25 Para la discusión entre las semejanzas y diferencias entre los conceptos de liberalismo y republicanismo en este contexto vid. Andreas Kalyvas y Ira Katznelson, Liberal Beginnings. Making a Republic for the Moderns, op. cit. pp. 8-9.

26 Durante la noche del 4 al 5 de agosto, la nobleza y el clero abandonaron sus privilegios. A través de diversos decretos fechados entre el 5 y el 11 de agosto, la Asamblea constituyente decidió la abolición del régimen feudal, la igualdad en los impuestos y la desaparición del diezmo. Antoine Barnave pertenecía al club de los Feuillants, y defendia una monarquía compatible con un sistema de representación fuertemente censitario. Fue guillotinado durante el Terror, a los 32 
atentados a la propiedad salvo la incautación de los bienes de los emigrados y condenados por la Revolución. Y se desarrolló incluso una ideología del buen propietario republicano, alejado del terrateniente absentista del Antiguo Régimen y próximo al granjero de la Revolución americana. La tierra, regada con el sudor de hombres libres y cultivada con técnicas modernas y eficientes, ofreceria un futuro de prosperidad más deseable que la procedente del comercio, que amasaba riquezas con artículos de lujo y bienes superfluos y corrompía la sociedad con su ambición y su dinero ${ }^{27}$. Los efectos positivos del doux commerce, que tanto había predicado Montesquieu ${ }^{28}$ no se concibían en este tipo de ideología, más cercana al ideal clásico y roussoniano que a la modernidad manufacturera y expansionista. Incluso Benjamin Constant, gran defensor del comercio y de la total libertad individual, defiendió, hasta fecha tan tardía como 1815, que los derechos políticos se adquirieran únicamente por medio de la propiedad de la tierra, y no de rentas industriales o financieras ${ }^{29}$. Y aunque todos los autores desgranan una serie de argumentos en favor de la propiedad agraria -riqueza radicada en el país, menos sometida a los azares del mercado, regida por la constancia y la prudencia y no por la temeridad- hay en esta defensa un objetivo de continuidad en medio de la ruptura revolucionaria: restaurar el orden social. La tenencia de la tierra será, como en el Antiguo Régimen, la base del poder económico, pero ahora en manos de propietarios republicanos formando una nueva aristocracia, ya no de la sangre sino del mérito personal.

Esta es desde luego la intención explícita de Madame de Staël cuando, en sus Circunstancias, dedica un apartado especial a la propiedad:

\begin{abstract}
"Los muy escasos demócratas babouvistas, los muy numerosos maleantes políticos, los aristócratas que esperan destruir el principio de igualdad exagerando sus consecuencias, pretenden que la destrucción de la propiedad se basa en las mismas razones que han derribado la esclavitud, el feudalismo y la herencia. Nada en el mundo puede ser más absurdo. Todas las verdades poseen dos fuerzas distintas, como la naturaleza de la que emanan: la fuerza destructora y la fuerza creadora [...] Si no existiese la institución de la propiedad para servir de base a la sociedad no podría creer en la abolición de la herencia. [...] La propiedad es el origen, la base y el vínculo del pacto social.... La propiedad y la sociedad son un sola y misma cosa"30.
\end{abstract}

años. La cita pertenece al discurso pronunciado en la Asamblea el 15 de julio de 1791. La traducción es mía.

27 James Livesey, "Agrarian Ideology and Commercial Republicanism", Past and Present, $\mathrm{n}^{\circ}$ 57, 1997, pp.94-121.

28 Marco Platania,: "Dynamique des empires et dynamiques du commerce: inflexions de la pensée de Montesquieu (1734-1802)", en Revue Montesquieu, nº 8, 2005-06, pp. 43-67.

29 Benjamin Constant, Principes de Politique applicables applicables à tous les Gouvernements représentatifs, en Oeuvres, Paris, Gallimard, 1957, pp. 1116-1117 (hay edición española en Madrid, Centro de Estudios Políticos y Constitucionales, 1989). Más tarde, en 1818, en sus Réflexions sur les constitutions et les garaties, modificará su opinión y otorgará a los industriales los mismos derechos politicos que a los propietarios.

30 Circunstancias, p. 101. Sobre el preeminente lugar que ocupa la propiedad en el texto de Madame de Staël vid. Gérard Gengembre y Jean Goldzink, "La République bien ordonnée commence par l'individu propriétaire: Des circonstances actuelles de Madame de Staël, Cahiers staëlines, $\mathrm{n}^{\circ}$ 58, 2007, pp. 111-119 
Sin embargo su proyecto no es totalmente censitario. De hecho, nos dice que en el mundo hay dos intereses elementales: la necesidad de adquirir y la de conservar, el interés de los no propietarios, propio de los jóvenes que inician su carrera, de los espíritus innovadores, y el de los propietarios, de la generación en la plenitud de la vida que solo aspira ya a la tranquilidad y el disfrute pacífico de sus bienes ${ }^{31}$. Proteger a unos y a otros, hacer que ambos estén representados en las instituciones, esa es la tarea primordial de un gobierno estable, la base firme en la que asentar la República. Por eso propone la elección libre de la cámara baja, el Consejo de los Quinientos, que serán elegidos por el pueblo, "porque de él depende todo el sistema representativo"32. Filtrar candidatos o condicionar las elecciones en función de los intereses republicanos, como se ha hecho bajo la Constitución del año III, es falsear el sistema y debilitarlo al perder la confianza de los ciudadanos: sería preferible privar al pueblo de sus derechos políticos antes que "hacerle jugar a las elecciones como los niños juegan a las casitas", legitimando lo que no es fruto de su voluntad, en una mezcla de hipocresía y despotismo que suma los inconvenientes de todos los gobiernos. " Nada hay en el mundo más indicado para desacreditar ante el pueblo el sistema representativo que el proclamar los principios ilimitados de la libertad en los que aquel se funda y recurrir a todas las sutilezas, a todos los sofismas, a todos los actos arbitrarios para manejar las elecciones"33. "Los tiranos gobiernan sin engañar, los jefes populares arrastran en lugar de gobernar"34.

Pero la elección libre termina en la Cámara baja. La Cámara alta, el Conseil des Anciens, será el bastión a la vez del pedigrí revolucionario republicano y de la propiedad vertebradora de la sociedad. Eliminando cualquier sutileza y sofisma para no caer en lo que acaba de criticar, Mme. de Staël proclama que "el mantenimiento de la propiedad en un país como Francia, exige sacrificios del principio metafísico de la libertad, puesto que para conservarla, es preciso poner el poder en manos de los propietarios"35 . Y, además, "en Francia es necesario conservar algunas parcelas del poder conservador en manos de los republicanos"36. Esa doble condición de riqueza y fidelidad a los logros revolucionarios debe constituir el núcleo central del sistema político, y reflejarse a las claras en la constitución, para que no tenga que ser continuamente violada: Cuando "los progresos del espíritu público" hagan posible una mayor democratización se podrán eliminar las condiciones de elegibilidad para los cuerpos legislativos, pero no ahora: "La República ha sido instaurada cincuenta años antes de que los ánimos estuviesen preparados para ella (...) Los republicanos saben que el resultado de las elecciones, abandonadas a sí mismas, sería muy desfavorable al mantenimiento de la República"37. Para evitar el golpe

\footnotetext{
31 Circunstancias, p. 165.

32 Ibid. 156.

33 Ibid. p. 158.

34 Ibid. p. 166.

35 Ibid. p. 157.

36 Ibid. p. 158.

37 Ibid
} 
de estado hay que incluir el golpe de estado en la Constitución: "Tenéis que escoger entre la dictadura de las instituciones y la de las persecuciones, y yo prefiero con mucho la primera" 38 .

La dialéctica continuidad/ruptura aparece aquí con una nueva formulación. Todo el combate contra la monarquía absoluta se fundamenta en la búsqueda de la modernidad para Francia, en la adecuación de las instituciones a los tiempos, en la obsolescencia de los modos del Antiguo Régimen. Sin embargo Madame de Staël denuncia también un avance excesivo, la imposición de una modernidad -la democrática, con elecciones libres y directas- que está más allá del tiempo presente, y que es por ello tan dañina como el empeño de mantener el pasado. Este argumento del avance excesivo de las instituciones politicas aparece con frecuencia en sus reflexiones, en la convicción de que solo hay que prestar atención al presente, sin apuestas de futuro y sin nostalgias ni de la dulzura de vivir pre revolucionaria ni de de las repúblicas de la Antigüedad que gozaron de una democracia directa que hoy ya es imposible, y, lo que es más importante, indeseable.

En este contexto aparece una de las primeras distinciones entre la libertad de los antiguos y la de los modernos, que su amigo Constant hará famosa algunos años después ${ }^{39}$, y que está ya bien esbozada en el texto de Madame de Staë140. En la Antigüedad no existía, como ocurre en los grandes estados actuales, "una masa de hombres pacíficamente egoístas (...) que puede trazar su destino al margen de los acontecimientos públicos". En Francia, continúa, la opinión pública estará basada, no en el patriotismo que hacía funcionar las repúblicas de Esparta, Atenas o Roma, sino "en el amor al reposo, en el deseo de adquirir fortuna, en la necesidad de conservarla". En Roma, "siempre brotaba el entusiasmo cuando se proponía el sacrificio del interés personal ante el interés general... porque la porción individual de cada uno resultaba menor que la obtenida de la cosa pública.... Pero en Francia, donde ocurre todo lo contrario, es el respeto por la existencia particular, por la fortuna privada, lo único que puede hacer amar la República"41

Un amor que debe cultivarse y defenderse en la Cámara alta, el Conseil des Anciens, el órgano conservador por naturaleza, conservador de los logros revolucionarios, de los valores republicanos y de la excelencia y el talento de los mejores. Con un mandato vitalicio, al menos para la generación que ha sido artífice de la Revolución, se debería reclutar en el futuro entre los grupos de mayor peso social: militares, hombres de letras procedentes del Instituto, y propietarios. Centro director y moderador de toda la vida politica, sus miembros tendrian la existencia asegurada por una generosa asignación económica, sin

38 Ibid. p. 158.

39 Benjamin Constant, De la liberté des anciens comparée à celle des modernes, Paris, 1819. Hay traducción española en B. Constant, Escritos políticos, Madrid, Centro de Estudios Políticos y Constitucionales, 1989.

40 Por las mismas fechas y en los mismos círculos Charles-Guillaume Théremin recogía también esta distinción entre la libertad de los antiguos y la de los modernos en su obra De l'incompatibilité du système demagogique avec le système d'économie politique des peuples modernes, publicada en 1799. Vid. Andrew Jainchill, Ramainings Politics after the Terror., op. cit., pp. 114 y ss.

${ }^{41}$ Circunstancias pp. 130 y ss. 
temor a perder el cargo dada su designación de por vida, y sin más intereses que el mantenimiento del sistema, es decir la estabilidad politica. Este cuerpo, que asumiría también las tareas de un Tribunal Constitucional ${ }^{42}$, estaría cerca de ese legislador sabio y desinteresado que tanto gustaba a Rousseau. Un eco de la "virtud republicana", del viejo ideal de moralidad politica del republicanismo clásico, sigue latiendo en esta propuesta de Madame de Staël, para que la línea que divide a los antiguos de los modernos no sea tan nítida como los estudiosos quieren verla con frecuencia. Es también una propuesta que suele llevar a calificar el modelo de Germaine Necker de "republicanismo aristocrático"43, calificación que no rechazaría su autora por ser la aristocracia del talento, única razón, junto con la propiedad para aceptar desigualdades sociales ${ }^{44}$. Y un modelo que tampoco está muy lejos del sistema de listas de notables, previas a una elección restringida, que se adoptará poco después, durante el Consulado, respaldadas por Roederer, ideólogo y amigo de Madame de Staël. Citando a Rousseau, Roederer acepta la denominación de aristocracia electiva para su propuesta censitaria con listas de notables, puesto que el término aristocracia significa el gobierno d los mejores pero sometidos, en este caso, a una elección. Y dado que la democracia en una nación moderna -sigue Roederer- no puede ser ya directa sino representativa, y no es en puridad el gobierno de todos sino de una parte de los ciudadanos, el resultado, dice, es que "aristocratie élective et démocratie répresentative sont donc une seule et même chose. Ansi, demander si la notabilité n'est pas l'institution d'une aristocratie élective, c'est demander si elle n'est pas l'institution d'une démocratie répresentative" 45 . De esta forma, la aristocracia electiva sustituye a la nobleza hereditaria. Solo se sacrifica el privilegio del nacimiento, pero se mantiene la necesidad de la institución. Conclusión que, aunque formulada en 1801 en apoyo del régimen de Bonaparte, no hubiera disgustado en absoluto a Madame de Staël. El republicanismo sigue mostrando múltiples facetas.

\section{LA FIRMEZA DEL EJECUTIVO}

Todas estas cautelas para evitar los desmanes de asambleas radicalizadas a la derecha o a la izquierda, no hacen del legislativo la pieza principal de una buena constitución, en opinión de Madame de Staël. Esa pieza ha de ser necesariamente el poder ejecutivo. Si la Constitución del año III fue quebrantada varias veces se debió a la mala organización de éste, a la desconfianza que generaba y al empeño en hacer de él un mero servidor, ejecutor, del legislativo, sin fuerza y sin consideración moral: sin fuerza porque sus agentes podrian desobedecerle sabiendo que sus órdenes se han hecho contra la voluntad de quien las dicta; sin consideración moral porque se vería obligado a ordenar lo que

\footnotetext{
42 Ibid. pp. 158 y ss.

43 Andrew Jainchill, Ramainings Politics after de Terror, op. cit., p. 129.

44 "Es necesario, dice Mme. de Staël, que [los republicanos] adopten algunas de las ideas de la aristocracia para establecer sólidamente las instituciones populares. Los demócratas saben conquistar, los aristócratas conservar". Circunstancias, p. 160.
}

45 Roederer, "Discours concernant le projet de loi présenté pour le Gouvernement pour la formation des listes de notabilité", 13 Ventôse, An IX (4 de marzo de 1801), en OEuvres, vol. VII, p. 140 . 
desaprueba. El poder ejecutivo, el Directorio en este caso, siempre debe ser considerado como un representante de la nación y no como el delegado del cuerpo legislativo. Cuando éste lo elige se comporta con respecto a él como una simple asamblea electoral ${ }^{46}$.

La influencia de Jacques Necker se manifiesta aquí de manera clara 47. Acostumbrado al ejercicio del poder y a las ventajas de un sistema de despotismo ilustrado, Necker no alberga ilusiones filosóficas respecto a la política. Un gobierno no tiene otra finalidad que la de garantizar una convivencia pacífica para que la producción de bienes y servicios pueda alcanzar a las necesidades del conjunto de la población. Considerando que solo los propietarios están en condiciones de producir bienes materiales, la protección de los intereses de este grupo es tarea primordial de cualquier gobierno, aunque el fin último sea el bienestar general. Desde este punto de vista, un buen gobierno debe ser siempre un gobierno fuerte, sea cual sea el ordenamiento constitucional y la forma exterior que adopte: monárquica o republicana. El ejecutivo debe ser la "fuerza motriz"; representa, en el sistema político, ese poder misterioso que, en el hombre moral, aúna acción y voluntad, aunque deba ser también un gobierno controlado para evitar la arbitrariedad y la tiranía ${ }^{48}$. Madame de Staël, en esa misma línea, desea que el Directorio tenga veto suspensivo sobre las leyes emanadas del legislativo, posibilidad de disolución de las cámaras y convocatoria de nuevas elecciones o, al menos y en último caso, posibilidad de dimisión de los Directores aunque no sea el momento previsto para su renovación legal. De otra forma, la única alternativa a la ejecución de leyes contra su voluntad será la violación continua de la Consitución. A quienes se escandalicen por conceder demasiados poderes al ejecutivo Madame de Staël les dice: "Qué preferís? ¿El veto suspensivo y el poder de disolución o el 18 Fructidor?"49.

Al conceder el voto suspensivo no importa ya quitar al ejecutivo la iniciativa legislativa. Aunque sea un ejecutivo fuerte debe ser un ejecutivo controlado y no debe tomar decisiones al margen de la Cámara en materia de leyes. Puede, eso sí, elegir a sus ministros de entre los diputados, de forma que la Cámara estuviera en cierto modo representada dentro del propio ejecutivo. Mantiene que sea un órgano múltiple, formado por tres, cinco o siete miembros; es más, se hace de esta cuestión uno de los principios esenciales "del espíritu de la Revolución", porque "en Francia ningún hombre que no fuera rey sería aceptado en solitario al frente del gobierno, y todo hombre que fuera aceptado querría convertirse en rey"50. Esta solución, avalada hasta cierto punto por Sieyès ${ }^{51}$, aunque por razones más complicadas como veremos, se convirtió en la fórmula republicana

46 Circunstancias pp. 169-170.

47 Para la influencia de Necker vid. Henri Grange, "Necker, Madame de Staël et la constitution de l'an III", en VV.AA., Approches des Lumières. Mélanges offerts à Jean Fabre, Paris, Klincksieck, 1974

48 Jacques Necker, Du pouvoir exécutif dans les grands états, en Oeuvres Complètes , Paris, Treuttel et Würtz, 1821, vol. VIII, p. 15.

49 Circunstancias, p. 170.

50 Circunstancias p. 156.

51 Emmanuel Sieyès, " Opinion de Sieyès sobre varios artículos de los títulos IV y V del proyecto de Constitución", en Escritos y discursos de la Revolución, op. cit., pp. 265 y ss. 
Madame de Staël y la Constitución del año III: el nacimiento del republicanismo liberal

por excelencia para el poder ejecutivo, a pesar de que ocasionó numerosos problemas durante el periodo del Directorio.

Era también frecuente en la época considerar al poder administrativo en parte separado y en parte dependiente del ejecutivo propiamente dicho. Constituido fundamentalmente por los prefectos de los departamentos provinciales creados por la Revolución, la Constitución del año III los consideró cargos de elección popular, si bien el Directorio podia destituir a esos agentes y nombrar directamente otros en su lugar. Esta combinación de elección y designación indignaba a Madame de Staël porque veía en ella una degradación del sistema electoral en general, convertido en mera comedia a los ojos de los electores cuando el gobierno destituía a quienes los ciudadanos habian elegido. En un gobierno republicano, decía, que es representativo por su propia naturaleza, no es necesario que los agentes de la administración sean de elección popular, pero si se mantiene ese carácter, se podrá restringir sus funciones pero nunca destituir a quienes han sido elegidos.

En cuanto al poder judicial, también de carácter elegible según la Constitución, Madame de Staël quiere a los jueces más independientes, tanto del poder popular como del poder ejecutivo. Además de su preferencia por la introducción del jurado, considera que el nombramiento de jueces debe tener un carácter vitalicio, y que los miembros del Tribunal Supremo sean miembros a la vez de la Cámara alta y que sea ésta la que juzgue los crímenes de alta traición y de prevaricación de los funcionarios. 52

El conjunto de los poderes del estado debe funcionar de manera armónica, lo cual no implica que deba existir una división de poderes según el modelo de Montesquieu ${ }^{53}$. En este punto se aúnan la influencia de su amigo Enmanuel Sieyès, y de su padre, Jacques Necker. Ninguno de los dos defendía la visión continental de lo que era la división de poderes en Inglaterra. Difundida, además de Montesquieu, por la obra de Jean-Louis de Lolme en las últimas décadas del siglo XVIII ${ }^{4}$, Necker creía que poco tenía que ver con el funcionamiento real del sistema británico, en el que el monarca tenía mucho más poder que el que querían aceptar los liberales del continente 55 , obsesionados con la idea de la soberanía popular, encarnada en el parlamento, y que veían siempre en el

52 Las reflexiones sobre el poder administrativo y el judicial están en pp. 170 y 172 de las Circunstancias

53 Una discusión sobre Mme. de Staël, Constant y la división de poderes se puede encontrar en K. Steven Vincent, "Liberal Pluralism in Early Nineteenth Century: Benjamin Constant and Germaine de Staël", en J. Wright and H.S. Jones, Pluralism and the Idea of the Republic in France, London, Palgrave MacMillan, 2012.

54 Jean-Louis De Lolme, Constitution de l'Angleterre, ou État du gouvernement anglais, comparé avec la forme républicaine et avec les autres monarchies de l'Europe, 1771. La obra de De Lolme conoció numerosas ediciones en las últimas décadas del siglo XVIII y primeras del XIX y tuvo una gran influencia en el pensamiento politico europeo, y especialmente en Francia, pero ofrecía una visión un tanto distorsionada del funcionamiento real del sistema inglés.

55 Las investigaciones recientes estarian más en la línea interpretativa de Necker que la que hacian muchos de sus contemporáneos. Vid. Jeremy Black, The politics of Britain. 1688-1800, Manchester and New York, Manchester University Press, 1993. La influencia del modelo de Montesquieu y su crítica en los últimos años del siglo XVIII se puede ver en Annelien de Dijn, French Political Thought from Montesquieu to Tocqueville. Liberty in a Levlled Society?, Cambridge University Press, 2008. 
ejecutivo al enemigo a combatir. La fiscalización y el control de los actos del gobierno, tal como la realizaba el parlamento de Westminster con gran éxito durante el reinado de Jorge III, les parecía a los liberales de matriz revolucionaria una tarea escasa para los altos fines asignados a la voluntad general expresada a través de representantes libremente elegidos. Sin embargo Necker se dejaba impresionar bastante poco con las grandes palabras y distinguía entre la voluntad y el deseo de una nación. La primera no es otra cosa que la decisión momentánea de los individuos que constituyen la generación del presente, y es la que hace y deshace las mayorias en la Cámara a través de las elecciones; el segundo, es una entidad de generaciones sucesivas y trascendente a ellas; expresa la tendencia a perseverar en el ser de una comunidad contemplada en el transcurso de los siglos. La autoridad politica, con independencia de los individuos que la ejercen en cada momento, tiene como misión realizar el deseo de una nación, y no debe por tanto someterse a la voluntad de una asambleas contingentes y efimeras ${ }^{56}$. Sieyès por su parte, criticaba la división de poderes establecida por Montesquieu porque enfrentaba a unos poderes con otros, perjudicando la "unidad de acción" que debe presidir la actividad del Estado. Frente a lo que él denomina un "sistema de equilibrio" propone un "sistema de concurso" o de "unidad organizada", separando en múltiples funciones las tareas tanto del legislativo como del ejecutivo y encomendándolas a diferentes órganos $\mathrm{y}$ personas, independientes unos de otros, pero coordinados en la persecución de unos mismos objetivos políticos. No se trata tanto de que "el poder frene al poder", según la expresión de Montesquieu, sino de crear un complejo engranaje de relojería en el que cada pieza necesite de las restantes en su labor politica ${ }^{57}$.

Esta propuesta es la que hace suya Madame de Staël, citando a Sieyès aun sin nombrarle. "El equilibrio de poderes, dice, no es un peso contra otro, cosa que en otras palabras significaria un equilibrio de fuerzas que sin cesar impulsaria a hacerse la guerra para obtener una ventaja decisiva. El equilibrio de poderes es la serie de combinaciones que les lleva a estar de acuerdo, y solo la opinión pública puede, en un gobierno libre, obligar a uno de los dos poderes a ceder ante el otro, si por desgracia están en desacuerdo"58. No asume sin embargo, al menos no de manera explícita, todo el complejo engranaje que en Sieyès acompañaba a su modelo de equilibrio de poderes, dejando a la buena voluntad de todas las partes esa colaboración necesaria para que no degenere en un enfrentamiento. La propuesta se tiñe así de una cierta dosis de buenos deseos que plantea interrogantes sobre su buen funcionamiento en la práctica: una cámara conservadora de protección de la propiedad y de elección dirigida; otra cámara de elección libre destinada a albergar las propuestas innovadoras (sea por la derecha o por la izquierda) y un ejecutivo colegiado de 5 miembros y, por tanto, necesariamente diverso, que puede disolver las cámaras, abocado a frecuentes renovaciones en su seno, ¿podrán colaborar en el mantenimiento de la estabilidad política?

En todos los autores de la época -Sieyès, Necker, Roereder, Cabanis, Constant- se percibe la misma preocupación por la dispersión y el enfrentamiento

\footnotetext{
56 Jacques Necker, Du pouvoir exécutive dans les grands états, op. cit. p. 15.

57 Emmanuel Sieyès, " Opinion de Sieyès sobre varios artículos de los títulos IV y V del proyecto de Constitución", op. cit. pp. 251-272.

58 Circunstancias, p. 170.
} 
entre los poderes tras la desaparición de la monarquía, que garantizaba la unidad de acción del cuerpo político. Pero ni la crítica ni la admiración por el modelo inglés les lleva a introducir en sus propuestas la necesidad de partidos o grupos politicos, similar a los que ya existian en Inglaterra. El famoso pragmatismo inglés, que lleva al reconocimiento de intereses distintos, turnándose en el poder pero respetando el régimen político en el que todos están inmersos, no existe todavía en la Francia del Directorio, donde la polarización ideológica es mucho mayor. Los agrupamientos politicos son tachados de facciones y los intereses compartidos se denominan peyorativamente esprit de parti59. En realidad la única alternativa a una colaboración entre los poderes un tanto idealizada es el golpe de estado y la represión de los oponentes. Sin embargo, la opción moderada o centrista de autores como Madame de Staël o Benjamin Constant trata de construir un espacio entre esa polarización que acepte, sino los partidos políticos sí al menos distintas posturas conviviendo sin violencia. En esta actitud se ha querido ver el exacto significado del adjetivo liberal, que Constant empieza a utilizar en 1797, pocos meses antes del inicio de la redacción de las Circunstancias de Madame de Staë160 y que ella misma había recogido ya en $D e$ l'influence des passions sur le bonheur des individus et des nations, como lo opuesto a intolerante y fanático ${ }^{61}$

\section{MORAL, RELIGIÓN Y SOCIEDAD}

Todo este edificio constitucional ni siquiera puede imaginarse perdurable en el tiempo si falta la voluntad de la nación para conservarlo, la decisión de la sociedad para sostenerlo y la moral individual y colectiva para defenderlo.

Los años del radicalismo revolucionario y del Terror habían teñido la política de esperanzas frustradas y de ideales rotos. A partir de Termidor se busca una salida a la Revolución que recoja todo ese aprendizaje y que abandone utopias universales para salvar un presente incierto y una república frágil. La mayoría de los autores del momento creen que las claves para la estabilidad han de buscarse en el interés de los individuos y de los grupos, y en la flexibilidad de los principios para adaptarse a las cambiantes circunstancias. Madame de Staël, en cambio, se muestra más heredera de las Luces que fundadora del liberalismo decimonónico que está ayudando a formar. Quiere ir más allá de los acontecimientos, de los problemas y de las soluciones coyunturales. Quiere saber cuál es la relación entre ética y política, cómo fue posible el Terror, cómo pudo salir la barbarie de la ilustración, qué hay en el fondo del comportamiento humano para que los hombres hayan podido alejarse tanto de los sentimientos de humanidad y de fraternidad.

59 Vid. J.A.W. Gunn, When the French Tried to be British: Party, Opposition, and Quest for Civil Disagreement, 1814-1848, McGill-Queen's University Press, 2009.

60 Benjamin Constant, Des réactions politiques. Vid. Stephen Holmes, Benjamin Constant and the making of modern liberalism, Yale University Press, 1984, pp. 10-11.

61 De l'influence des passions sur le bonheur des individus et des nations, edición electrónica Amazon Kindle, 228-29. Para los diversos usos semánticos del término liberal y su traducción a otros contextos políticos, vid. Jörn Leonhard, "Language, Experience and Translation: Towards a Comparative Dimension", en Javier Fernández Sebastián (ed.), Political Concepts and Time. New Approaches to Conceptual History, Cantabria University Press, 2011, pp. 245-272. 
En los mismos meses en que redacta sus Circunstancias para proponer una reforma de la Constitución del año III, Germaine de Staël escribe De l'influence des passions sur le bonheur des individus et des nations para buscar otro tipo de respuestas, más allá de la mecánica politica: "Las pasiones, esa fuerza impulsiva que arrastra al hombre con independencia de su voluntad, ese es el verdadero obstáculo a la felicidad individual y política"62, afirmación muy en la línea de las preocupaciones del siglo XVIII, aunque rectificando en parte la exaltación que las Luces habían hecho de las inclinaciones pasionales. Para Madame du Châtelet tener "gustos y pasiones" era imprescindible para ser feliz ${ }^{63}$. Para nuestra autora sin embargo hay que saber apartar las pasiones si se quiere ser feliz, porque la gran satisfacción que procuran es efimera y decolora el resto de la existencia cuando desaparecen 64

Además, en el terreno social y político, las pasiones fuertes conducen al fanatismo, un concepto que alcanza en estos años el terreno político procedente de la crítica ilustrada a la religiosidad extrema. "El fanatismo, la más funesta de las pasiones, no es nunca otra cosa que el despotismo de una sola idea sobre la mente humana, y siempre es un principio vago y, por consiguiente, de extensión infinita". Es el resultado de la pretensión de aplicar ideas abstractas a la realidad, "ordenando los hechos", en el doble sentido de organizarlos según una idea filosófica previa, y de "darles órdenes", de pretender que los hechos se acomoden sea como sea a las reglas elaboradas previamente por los intereses o por las pasiones $^{65}$. El fanatismo es lo completamente opuesto a ese espíritu liberal que mencionábamos antes: el fanático es el intolerante, el intransigente, el radical, el que posee "espíritu de partido", de facción política.

Por eso llega a proponer cierto control sobre la prensa, sobre los periódicos que injurian e incitan a la revuelta permanente. La libertad no puede, en su opinión, amprarlo todo. Los libros ofrecen una reflexión más general y más reposada, y no han de encontrar trabas en su impresión y difusión, pero los periódicos "son un acto público que anuncia sucesos públicos, pueden inducir a error a los ciudadanos sobre lo que deben hacer, y son, no solo la parte más importante de la instrucción pública, sino un instrumento de gobierno o de agitación tan poderoso que no es posible sustraerlo a la vigilancia de la autoridad"; editar un periódico es además una actividad continuada y puede y debe ser suspendida provisionalmente antes de que se pronuncien definitivamente los tribunales. "Los periódicos, tal como son en Francia, tal como los han hecho los intereses y las pasiones del momento han producido $\mathrm{y}$ producirán todas las calamidades de Francia"66.

La agitación y el desorden que producen las pasiones mal encauzadas solo pueden frenarse con la moral y con la educación. El problema es que, según Madame de Staël, "la moralidad de los hombres precisa del vínculo de las ideas religiosas", especialmente en los hombres no educados, agitados ahora por las

\footnotetext{
62 De l'influence des passions sur le bonheur des individus et des nations, op. cit. 36-41.

63 Paul Hazard, El pensamiento europeo del siglo XVIII, Madrid, Alianza Universidad, p. 30.

64 Simonne Balayé, Madame de Staël. Lumières et liberté, op. cit. p. 55.

65 Circunstancias Segunda parte, cap. III.

66 Circunstancias, primera parte, capítulo IV.
} 
pasiones de la igualdad y por las divisiones de la opinión pública. Para las multitudes, la virtud republicana de amor a la patria y entrega a la comunidad no es suficiente. E incluso los hombres ilustrados necesitan de algo más, ya que al estar llamados a influir en mayor medida sobre el destino de sus semejantes, pueden producir mayores males con errores menos destacados ${ }^{67}$. Cuanto menor sea el poder de coacción del gobierno, cuanto mayor holgura tenga la máquina política, más necesaria será una guía tanto individual como colectiva. Asociada al Antiguo Régimen y a todos sus desmanes, la religión católica, que tiene además como cabeza a un extranjero, no puede, evidentemente, cumplir esta misión de moralización social. Quizá podría hacerlo una iglesia protestante, al estilo del calvinismo suizo: ceremonias sencillas pero con el halo de misterio que precisa la imaginación de los hombres, clérigos que no pueden ocupar cargos políticos y se consagran a la instrucción pública, amor por la igualdad y la libertad, y ausencia de un jefe extranjero. O quizá se acomode mejor con el espíritu francés una religión basada en la admisión universal del razonamiento como fundamento de todas las instituciones y todas las ideas, en los principios de una religión natural. Y en este sentido Madame de Staël piensa que la teofilantropía es "la institución más filosófica, es decir política y moral al mismo tiempo, que la Revolución haya establecido hasta ahora".

La teofiltropía era un movimiento deísta, inspirado en las ideas de Voltaire, de los free thinkers británicos, y en las teorias de Robespierre sobre el Ser Supremo y el culto a la Razón. Fundado por Chemin-Dupontés en 1796 y patrocinado por el Director La Réveillère-Lepeaux, enemigo declarado del catolicismo. Solo admitía dos dogmas, la existencia de Dios y la inmortalidad del alma, aunque conservaba los sacramentos del bautismo, la confirmación y el matrimonio como ceremonias simbólicas, organizadas en un principio por el jefe de familia, al no existir clérigos ${ }^{68}$. Debido a su origen, Madame de Staël la considerada demasiado "partidista", aunque sus prédicas, decía, pueden considerarse universales y atraer por igual al salvaje que al hombre civilizado, al sacerdote y al filósofo, en una línea muy volteriana.

Protestantismo o filantropía, deben ser en cualquier caso religiones nacionales, financiadas por el Estado y ligadas al régimen republicano nacido de la Revolución. La religión debe cumplir en Francia tres importantes tareas: servir de guía moral para el comportamiento individual, canalizar las necesidades espirituales y los sentimientos altruistas del ser humano, y establecer el vínculo entre religión y República, entre religión y virtud cívica, para que sea el último baluarte que defienda la Constitución cuando los argumentos jurídicos y los mecanismos politicos puedan fallar.

Algunos analistas han visto en estas consideraciones sobre la religión la prueba de que Madame de Staël está verdaderamente situada en unas Circunstancias actuales, como indica el título de su obra. Tanto las alusiones a la teofilantropía como al calvinismo responden a un momento muy concreto. La primera al auge que tomó esa secta precisamente después del 18 fructidor,

67 Todas las afirmaciones de Mmadame de Staël sobre la religión están recogidas en el capítulo II de la Segunda parte de sus Circunstancias.

68 Para el auge de la teofilantropía en el contexto de la efervescencia de sectas y cultos en Termidor vid. Bernard Plongeron (ed.) Le défis de la modernité, vol. X de Histoire du Christianisme, des origines à nos jours, Paris, Desclée, 1997, pp. 582-586. 
cuando se empezó incluso a enseñar en las escuelas, y que debió su ascenso al celo teofilantrópico de La Revéllière-Lepeaux, que fue sustituido en pradial del año VII (junio de 1799), iniciándose entonces su declive. La encendida defensa del calvinismo tendría que ver, según estos análisis, con el "orgullo ginebrino" de Madame de Staël en un momento en que los cantones de Ginebra y de Vaud habian sido anexionados a Francia69. Desde una perspectiva más general, también se puede apreciar en este alegato en favor de una religión nacional un rasgo más del republicanismo virtuoso, con toques roussonianos, que deja traslucir a veces la obra de Germaine Necker.

La moral debe encontrar también una buena alianza en la filosofia, en la buena filosofía. La filosofia ha sido la causa de la Revolución y su mala interpretación ha sido la fuente de todas las locuras, errores y crueldades que se han producido en su transcurso: "Hemos visto a los sectarios de la filosofia abandonar toda la teoría de la libertad a los hacedores de frases, y quedarse con los instrumentos claros y precisos del despotismo más absoluto y más sanguinario del que la historia nos ha dado ejemplo". Pero "como la teoría filosófica de la Revolución francesa es en sí misma indiscutible, no hay otro remedio para sus espantosos abusos que el lanzar torrentes de luces sobre los principios y su aplicación". "Los filósofos son los que han hecho la revolución y ellos son los que le pondrán fin"70.

Estas reflexiones sobre las pasiones, la moral, la religión y la filosofia hacen dificil calificar a las Circunstancias actuales y a su autora o bien de republicanas o bien de liberales, como si fuera posible esa disociación. Madame de Staël escribe para defender a los modernos individuos propietarios, iguales ante la ley y ciudadanos en un sistema representativo, pero la herencia ilustrada está todavía muy presente, una herencia basada en la virtud y, sobre todo, en la razón. Su obra termina con una "Conclusion" titulada precisamente "De la puissance de la raison", que se inicia diciendo: "Lorsque le degré de lumières dont on est susceptible rend tout à fait étranger à l'esprit de parti, l'on ne peut concevoir comment la raison, c'est-à-dire les idées justes sur toute chose ne frappent pas les hommes réunis"71. Le resultaba inconcebible que, alcanzado cierto grado de educación, la sociedad no se rindiera ante las evidencias de la razón. La experiencia revolucionaria no había desengañado del todo su espíritu de combate en pos de la verdad.

Fecha de envío / Submission Date: 10/03/2015

Fecha de aceptación / Acceptance Date: 14/04/2015

69 Lucia Omacini, "Introudction" a Les circonstances actuelles, op. cit. pp. XLV y XLVI.

70 Circunstancias, p. 215 y 216. Sobre la cuestión del lenguaje revolucionario y sus consecuencias vid. Gérard Gengembre y Jean Goldzink, "Terreur dans la langue. La question de la langue révolutionnaire d'Edme Petit á Madame de Staël", en Mots, n 21, 1989, pp. 20-31.

71 Les circonstances actuelles..., op. cit., p. 304. 